\title{
Methaemoglobinaemia after ingestion of amyl nitrite
}

\author{
R J Forsyth, A Moulden
}

\begin{abstract}
We report a case of methaemoglobinaemia in a 2 year old girl after ingestion of an 'aphrodisiac' containing nitrite. The availability of these products, their poor labelling, and their intended presence in domestic bedrooms all serve to increase the hazard they pose to young children.
\end{abstract}

\section{Case report}

A 2 year old girl was admitted deeply cyanosed. She was thought to have ingested about $5 \mathrm{ml}$ of a substance identified by her mother as 'Liquid Gold' approximately one hour previously. The bottle was unlabelled.

On arrival she was pale, drowsy, hypotensive, and tachycardic and cyanosed despite facial oxygen. Peripheral vasodilation was evident over the bridge of the nose and the dorsum of the hands and feet. Her respiratory rate was $26 /$ minute and air entry was unobstructed and adequate. Electrocardiographic monitoring indicated sinus rhythm at a rate of $130 /$ minute.

The Poisons' Information Centre at Guy's Hospital advised that Liquid Gold might contain an organic nitrite.

Circulatory compromise was managed with intravenous plasma. Arterial blood gas analysis showed an oxygen tension of $35.3 \mathrm{kPa}$ despite dark arterial blood and clinical cyanosis, and a diagnosis of methaemoglobinaemia was made. Intravenous methylene blue was given at a dose of $1 \mathrm{mg} / \mathrm{kg}$. Ten minutes later, the patient was centrally pink. Her conscious state improved and she became normotensive with a pulse rate of 100 / minute.

Subsequent analyses confirmed the poison to be amyl nitrite, and showed the methaemoglobin fraction of total haemoglobin on admission to be $\mathbf{0 . 4 3}$. Within three hours of arrival she was alert and orientated, and examination was normal. She was discharged home 24 hours after admission.

\section{Discussion}

Nitrites are widely used as aphrodisiac 'room odourisers' especially in the gay community, ${ }^{1}$ and are sold under such names as Liquid Gold and Quicksilver.

Nitrites are absorbed transdermally and by inhalation and ingestion. The effects are vasodilation, penile erection, dilation of other smooth muscle including the anal sphincter, reflex tachycardia, increased cerebral perfusion, euphoria, and methaemoglobinaemia. In excess, cardiovascular collapse ensues.

Methaemoglobin is formed by the oxidation of the iron in haemoglobin $\left[\mathrm{HbFe}^{2+}\right]$ to the $\left[\mathrm{HbFe}^{3+}\right]$ state. The resulting molecule is unable to bind oxygen resulting in an impair- ment of oxygen delivery to the tissues. Erythrocytes reduce naturally occurring $\left[\mathrm{HbFe}^{3+}\right]$ both by NADH dependent mechanisms, which represent $95 \%$ of the total activity under normal conditions, and NADPH dependent mechanisms, for which methylene blue acts as a cofactor, permitting increased activity of these latter pathways. ${ }^{2}$

Clinically, methaemoglobinaemia usually follows exposure to drugs or chemicals, nitrites being the most commonly reported cause. Neonates have an increased susceptibility to acquired methaemoglobinaemia, due to decreased activity of methaemoglobin reductase enzymes. Methaemoglobinaemia had also been reported after exposure to topical nitrites in disinfectants and dietary nitrates, which are reduced to nitrites by intestinal flora. We are unaware of descriptions of this increased susceptibility persisting beyond infancy. ${ }^{3}$

The diagnosis may thus be suspected from a history of exposure to an oxidant substance, and by the demonstration of a surprisingly high arterial oxygen tension given the apparent degree of cyanosis. Measured oxygen saturation will be low, but the saturation figure given by most gas analysers, which is calculated from the measured arterial oxygen tension assuming a normal dissociation curve, will be high. Arterial blood remains blue even after exposure to oxygen.

Treatment comprises ventilatory and circulatory support with volume expansion and intravenous methylene blue. An initial dose of $1-2 \mathrm{mg} / \mathrm{kg}$ is diluted and given over five minutes. A therapeutic effect should be seen within an hour. Methaemoglobin fractions of over 0.3 are usually symptomatic; fractions over $0 \cdot 7$ are incompatible with life.

Although methaemoglobinaemia after exposure to nitrites is well recognised, the ready availability through sex shops and the like of compounds containing nitrites increases the importance of familiarity with this fact. Such sales are not subject to regulation under the Medicines Act as no therapeutic effects are explicitly claimed, although sale to minors is prohibited by the Intoxicating Substances Supply Act 1985. Samples we have seen do carry hazard warnings, and describe their contents as alkyl nitrites, but on a plastic wrapper that is destroyed in opening. The result is an unidentifiable bottle left open in a bedroom as an 'odouriser'. It can only be a matter of time before another such bottle is found by an inquisitive toddler.

1 Haverkos HW, Dougherty J. Health hazards of nitrites. $A m \mathcal{F}$ Med 1988;84:687-90.

Ellenhorn MJ, Barceloux DG. Medical toxicology: diagnosis and treatment of human poisoning. New York: Elsevier, 1988 .

3 Feig SA. Methemoglobinemia. In: Nathan DG, Oski FA, eds. Haematology of infancy and childhood. Philadelphia: W B Sauders, 1987:641-54. 